\title{
I am what I am-Convergence Behaviors on Online Discussion about the Safety of COVID-19 Vaccines
}

\author{
Tung Bui \\ University of Hawai'i at Manoa \\ tungb@hawaii.edu
}

\author{
Quang Loc Lam \\ University of Hawai'i at Manoa \\ qllam@hawaii.edu
}

\begin{abstract}
Using data from an online discussion on the risk of getting blood clot from Johnson \& Johnson vaccine moderated by the New York Times Facebook page, we investigated the presence of eleven convergence behaviors, and the interaction between them. While recent research focuses on misinformation or fake news as the object of analysis, we argue in this exploratory research that it is equally important to analyze who and, whenever possible, why people engage in information exchange given a particular crisis, hence their convergence behaviors. Mapping the types of postings to their authors would be an additional step to design, develop, implement, and possibly, regulate online discussions for a more effective and just civic engagement. As we witness a mass manipulation of public opinion, our findings suggest that the number of netizens that seek to correct misinformation is growing. If the society goal is to swiftly rebut as many conspiracy theories as possible, we advocate for a dual social media control strategy: restrain as much as possible the misinformation spreaders/manipulators and encourage correctors to help propagate countervailing facts.
\end{abstract}

\section{Introduction}

Initially designed to promote information exchange and social connectedness, social media have become a favorite but also controversial platform with an increasing number of netizens seeking to spread and manipulate information for a variety of, and sometimes hidden, purposes. When a crisis event occurs, for example the news of the risk of getting a blood clot caused by a COVID-19 vaccine, people go to online media to get informed [1], [2]. Online news is easily accessible, free in many instances [3] and allows people to interact almost instantaneously with a large group of audience [4], [5].

However, there are inherent risks related to gather crisis-related information through social media [4], [6]. Actual facts could be interpreted differently or ambiguously on social media [7]. Social media is also known to be a convenient and tempting environment to spread rumors [8].

\section{Convergence behaviors in physical world}

In their seminal work, Fritz and Mathewson [9] described five types of "convergers": the returnees, the anxious, the helpers, the curious, and the exploiters. These people converge to a crisis site, such as a major natural or man-made disaster with a specific purpose. Kendra and Wachtendorf [10] suggested two more types of convergers: the fans (or supporters) and the mourners. Subba and Bui [11] identified the detectives as another type of convergers in their nine-month-long data collection of the 2010 Haiti earthquake.

The returnees survive the crisis event and decide to return to the affected area. They include residents, business owners or employees, friends or relatives of the victims [9]. Their motives are multiple. They come back to search for people they care for, to assess the losses, or to guard their properties [11]. The anxious may not be directly impacted by the event, but worry about relatives or friends in or around the impact area [9], [10], [12]. Although they are not affected by the crisis, the curious convene to the impact area investigating the situation [11]. And, the helpers congregate at the crisis site to offer assistance to the victims [9].

In any state of confusion, observers notice the presence of additional convergers. Exploiters emerge to take advantage of the vulnerable situation for personal gains [9]. They may steal or loot properties, or offer products or services at the expenses of the victims [11]. Fans or supporters express their gratitude or support to the rescuers or helpers while the mourners memorialize the victims [10]. They pray for the victims and lay flowers and light candles at the site(s) [11]. The detectives watch over the situation with an investigative mind and may take appropriate actions either in their official or unofficial capacities [11]. 


\section{Convergence behaviors on online platforms}

When people converge to an online platform, such as a forum to debate on a public health issues or to cope with a natural disaster, the returnees will join an "interest group" created for a specific discussion related to the crisis event [11]. In the case study of this paper, returnees shared their own safety experience with the COVID-19 vaccines. Online anxious include the seekers and the responders; while the seekers submit postings to reconnect with the victims they know, the responders answer to these postings [12]. The curious relentlessly scan the postings and the debate that follows [11]. While the helpers may provide helpful resources such as hotline numbers or wire funds to the needy [11], online exploiters attempt to advertise uncalled-for products or services [11]. In addition to texts, and pictures, video clips are often used by the fans or supporters to thank helpers or rescuers, and by the mourners to grieve the victims [11].

Bunker and Sleigh [13] identified the manipulators as a type of convergence behavior who create or alter information to either promote their personal agenda or to seek attention from other people by projecting themselves as people of power, intelligence, physical attractiveness, and a sense of entitlement and uniqueness" [14].

Subba and Bui [11] discovered the detectives as another type of convergence behavior whose mission is to detect or investigate possible source of suspicious information. Detectives challenge the manipulators and set out to denounce them.

The spreaders are the latest type of "converger" proposed by Leonardi et al. [15]. Spreaders aim to proliferate provocative or attention-grabbing information. As the re-transmitters of information [16], they circulate news provided by mainstream media or by other netizens they deem fortuitous to them. Spreaders' online postings are the results of their desire for informativeness, socializing, status seeking or selffulfillment [17]. As they seek to grow and nurture relationship with others, spreaders may not be aware of the correctness, or lack thereof, of the information they share. Some of the reasons that lead people to spread misinformation include the opportunity to self-express or socialize [18], the expected benefits and risks associated with the posting and the perceived trust in online information and information overload [19]. Hopp et al. [20] noted that people who share countermedia content on Facebook are positively associated with ideological extremity and negatively associated with the trust in mainstream news media.

Arif et al. [21] alerted the existence self-correcting crowd in the context of online rumors. As correctors seek to denounce misinformation, they exhibit most of the same psychology found in the spreaders, but they display an acute sense of concern and self-esteem. They find happiness when they were able to correct misinformation they caught online [12], [22]. They point out the information which is incorrect and/or provide the correct information or the source of information for other people to check. Correctors may correct the status or commentary of other people and write their own posts. In a study involving selfcorrecting crowd in Chinese social media, correctors often had to deal optimistic biases [23]. The impact of fighting misinformation is however not evident [24]. The correction of online misinformation would be more effective among those with higher initial misperceptions [25] or high or low conspiracy belief [26]. Health professionals are concerned about health misinformation on social media, but they rarely correct it [27]. There could be an overlap between helpers and correctors. To distinguish those two convergence behaviors, we analyzed the interaction between discussants on online platforms. Appendix 1 provides a synopsis of the behaviors' characteristics and some examples of these behaviors in the context of our case study-reaction to the blood clots news of the Johnson \& Johnson (J\&J) vaccine in the first days of its release.

\section{Information and misinformation}

In a typical crisis that has the potential to threaten the well-being of the general public, such as the case of providing information on the effectiveness and risks of a prescribed vaccine, one would expect at least a oneway communication from the authorities (e.g., the Center for Disease Controls and Prevention (CDC), or the drug manufacturers) to the potentially affected people (e.g., the general public interested in getting inoculated). Bunker et al. [14] noted, however, that these authorities tend to not pay sufficient consideration to the massive amount of discussion that proliferates on social media platforms, unless they are brought to their attention by major media agencies [28].

According to Molina et al. [29], real news include hard news (breaking news) and soft news (less timely information), which can be verified by their reliability, truthfulness and independence. Real news can be assessed by features such as the factuality, evidence, message quality, sources of the content, metadata indicators of authenticity [29]. A real news usually is fact-checked and composed in a professional journalistic style with verified sources; it is written in past tense and is edited and proofread [29]. On the other hand, a false news is news that is intentionally fabricated and is often used to propagate conspiracy theories [29]. False news on social media can be found to be often not factual, usually with grammatical, 
spelling or punctuation mistakes; it likely lacks verified sources with no quotes or made-up quotes [29].

Zhou and Zafarani [30] noted that although there is no universal definition for fake news, a piece of news is deemed fake when it is proven to be false information regardless of the motives behind. Research shows that for most netizens, as information receivers, are overloaded, vulnerable and, more often than not, irrational, and they experience difficulty in differentiating between truth and falsehood [30].

Manipulators and exploiters have learned to mix truth with misinformation or missing context to confuse the readers and even to gain their trust. Reporting some truth is one of their strategies to attract people to the misinformation they seek to perpetuate. Figure 1 shows examples of some frequent features of misinformation on online discussion in red boxes.

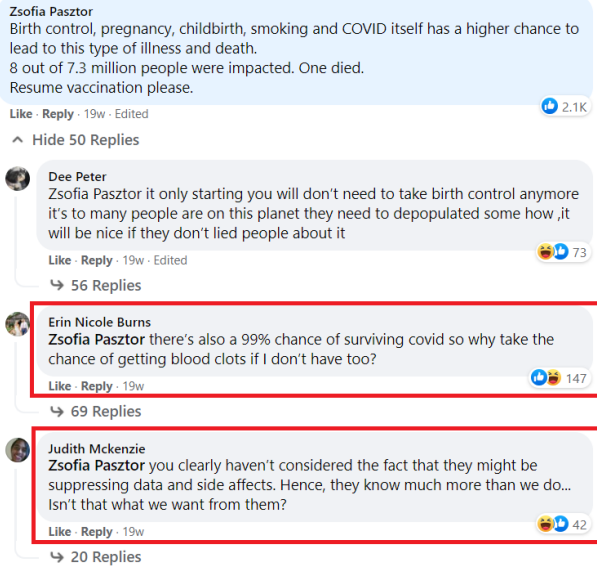$$
\text { (4) }
$$

\section{A Case Study: New York Times's Facebook discussion on $\mathbf{J} \& J$ vaccine risk of blood clot}

\subsection{Research site}

As COVID-19 ravages the world, it is widely accepted that vaccination is the only way to contain the pandemic. However, there remains a significant number of citizens who have concerns about unknown side effects with vaccines that have been released only under "emergency use" by the Food and Drug Administration (FDA). They raise doubts and anxiety about getting inoculated. On April $12^{\text {th }}, 2021$, the FDA recommended pausing J\&J COVID-19 vaccine nationwide after six cases of rare blood clot were reported. These cases led to two deaths. Some statisticians would argue that the fatalities, although detrimental to the deaths and family members, as insignificant given the millions of administered vaccines. Nevertheless, the case was perceived as a real crisis. It was unexpected and it caused fatalities. The swift reaction by the CDC to halt the vaccination added more confusion to the suspicious population, anxious to protect themselves from the pandemic. Shortly after on April 18th, The New York Times (NYT) posted an article on its Facebook (FB) page: 'We're flying blind': A Doctor's account of a woman's J.\&J. vaccine related blood clot case. This article indicated that the blood clot disorder was rare but severe, and the J\&J vaccine was on hold.

\subsection{Research methodology}

With the ability to collect massive amount of data on social media, ethnography, webnography, or cyberethnography has increasingly gained popularity as an empirical, unobtrusive, and reliable approach to study online communities and their roles, functions and impacts on business and society through netizens' generated media. Furthermore, since digital data are universally accessible, many researchers could independently verify and validate the analysis and findings of their colleagues [31]. Our research plan was to look for convergence behaviors when netizens react to information or misinformation on vaccination decisions.

We chose the NYT online Facebook platform for our research. Facebook allowed us to download all the postings, to include the publicly available demographics of the participants. The NYT enjoyed an established reputation as a credible news source and its readership is known to be aimed primarily at the literate, thus reducing the possibility of having "noise" from people just posting unrelated or irrelevant conversations. Specific features of FB were also recorded, such as the number of "likes", "replies", dates and times of the postings, and emoticons.

Within a week, the post by the NYT generated approximately 1,800 comments from FB users. We downloaded the comments manually and devised a coding scheme to categorize and classify all the convergence behaviors that we presented earlier. Because of FB users' privacy settings, we could only collect 1,257 comments from 711 users in the NYT's post. The highest number of posts by a single user was 41 while the lowest number of posts by a single user was one. Most of the postings appeared on the first day (i.e., 1,150 comments) and quickly diminished in the next following days. As the NYT promptly posted emerging news on their FB page, discussion on the blood clot effectively ended within a week.

To identify convergence behaviors, we performed a content analysis on all 1,257 comments, replies and emoticons using a coding rule based on the classified characteristics of the convergence behaviors. 


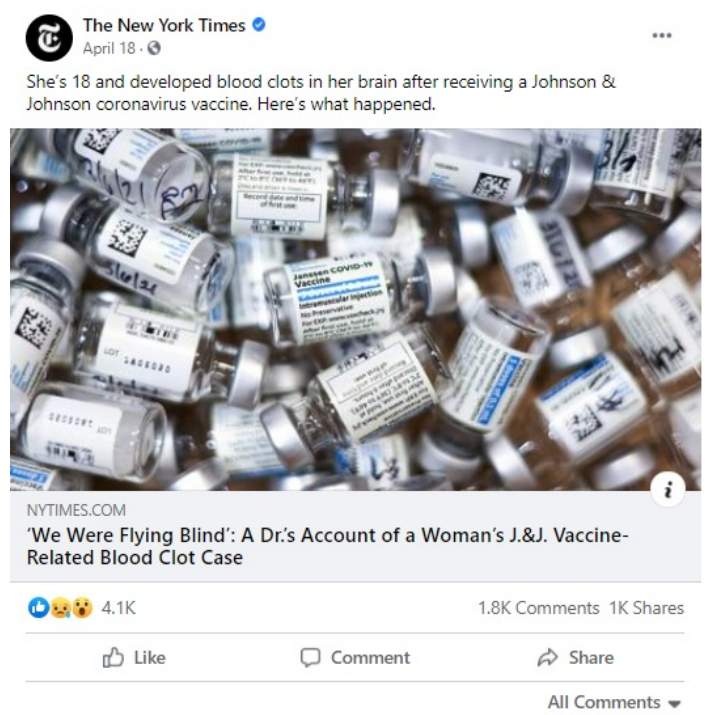

\subsection{Data description}

An event can be classified as a crisis if it occurs as a surprise to the involved parties, has the potential to threaten one or more valued goals, and requires immediate actions [32], [33]. To verify and validate that the chosen case study would qualify as a crisis, we performed a simple word cloud of all the postings (Figure 3). The netizens ("people") seemed to converge in a crisis state, focusing on a shared concern ("vaccine", "blood clot"); a real public crisis if blood clots turn out to be a severe threat ("risk"; "side effects", "die/dead/died").

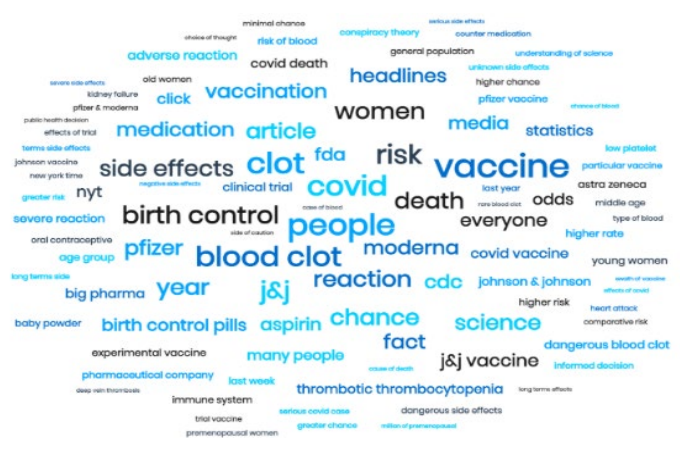

Two coders were assigned to the data analysis. Prior to the coding, they studied the information provided by the CDC as a source for real information. They were given the background theory on convergence behaviors, asked to review the literature, and studied coding techniques based on published case studies. Data collected were a combination of texts, images, videos, and geographic information data [34], [35]. The first coder performed the coding manually. The second one conducted a peer-checking task on a subset of random postings as recommended by [36]. Comments were binary-coded based on their contents. If a comment had its content assessed as a helper, a value of 1 was assigned to the helper category for that comment; otherwise, it would receive a value of 0 . Some postings exhibited more than one convergence behavior; they were given values of 1 to as many categories as they were deemed qualified.

We also studied the reply function on FB to observe how a subscriber argued with another person. Then, we matched the convergence behaviors with the profiles of the users ("information about users").

After the first round of coding and a lapse of time of eight days, the first coder re-coded two additional times-a total of three rounds of coding. The second round of coding applied to all postings $(1,257)$, and the third round was needed to enhance robustness in the classification. 196 codes were re-classified in the second round, as the coders gained a better understanding of the conversation styles in the postings. There was a significant amount of typographical and syntax errors in the postings. In the third round, only 54 reclassifications were needed due to the indistinguishable wording by the correctors and helpers. Classifications were recorded on a spreadsheet together with some limited demographic information made available from the FB platform, to include gender, profession, and age through posted photos.

We performed a series of correlation analyses. The initial correlation analysis was conducted on all individual 11 behaviors. It resulted in low values. We incrementally iterated the analyses with combined behaviors up to four (Table 2 in Section 6). We also analyzed the profiles of the people who posted the comments. We first reviewed their Facebook profile and rated the quality of their writing.

Using Molina et al.'s classification [29], we segregated the real news from the fake news based on features such as how FB users cite the sources of their postings, the verification of the sources, the statistical data or research based information in their posts, the topic interest, and other factors mentioned earlier.

\subsection{Presence of convergence behaviors}

Table 1 provides a snapshot of all convergence behaviors and their percentage of comments and users. There were a few FB users who posted more than one comment.

The majority of the returnees $(5.89 \%$ of comments and $9.85 \%$ of users) in the NYT postings were the people who already took the vaccine and wanted to debate on the vaccine safety. Many returnees expressed 
their intention or have scheduled to take the vaccine, and they came to the discussion thread to help them make the final decision.

The anxious $(6.05 \%$ of comments and $8.02 \%$ of users) felt confused or scared of the blood clots. They expressed their fearful feelings as they worried for their health and that of their families. The decision dilemma was perceptible. While the anxious were afraid of the blood clots caused by vaccine, they feared they would get infected if not getting inoculated. Our content analysis shows that the information provided by many FB users did nothing but further confused the fearful. As evidenced by their postings exposing their lack of scientific understanding, the anxious felt hopeless in their effort to check the validity of posted information, which aggravated their panic.

Table 1. Frequencies and percentage of convergence behaviors

\begin{tabular}{|l|r|r|r|r|}
\hline $\begin{array}{l}\text { Convergence } \\
\text { behavior }\end{array}$ & $\begin{array}{l}\text { Total no. } \\
\text { of } \\
\text { comments }\end{array}$ & $\begin{array}{l}\text { Percent of } \\
\text { comments }\end{array}$ & $\begin{array}{l}\text { Total } \\
\text { no. of } \\
\text { users }\end{array}$ & $\begin{array}{l}\text { Percent } \\
\text { of users }\end{array}$ \\
\hline Returnees & 74 & $5.89 \%$ & 70 & $9.85 \%$ \\
\hline Anxious & 156 & $6.05 \%$ & 57 & $8.02 \%$ \\
\hline Helpers & 136 & $10.82 \%$ & 109 & $15.33 \%$ \\
\hline Curious & 19 & $1.51 \%$ & 6 & $0.84 \%$ \\
\hline Exploiters & 49 & $3.90 \%$ & 45 & $6.33 \%$ \\
\hline Fans & 45 & $3.58 \%$ & 42 & $5.91 \%$ \\
\hline Mourners & 39 & $3.10 \%$ & 33 & $4.64 \%$ \\
\hline Detectives & 82 & $6.52 \%$ & 60 & $8.44 \%$ \\
\hline Manipulators & 182 & $14.48 \%$ & 133 & $18.70 \%$ \\
\hline Correctors & 45 & $3.58 \%$ & 20 & $2.81 \%$ \\
\hline Spreaders & & & & $16.46 \%$ \\
\hline
\end{tabular}

Helpers were the second most popular convergence behaviors in this NYT posting $(12.41 \%$ of comments and $16.46 \%$ of users). They aided other FB users by providing information to the public as well as to offer assistance if requested. Some helpers quoted other sources of information in their comments and supplemented with their own. They answered the questioned raised by the anxious and suggested different solutions to help the returnees make their decisions. They frequently argued that a vaccine was not only good for those inoculated but also necessary for the community to prevent the spread of the virus. The education section on their Facebook profiles showed that most helpers seem to have high education background; as well as the logical arguments in their comments showed that they demonstrated a good understanding about statistics. While they realized the danger of blood clots, they also understood that the risk of blood clot occurrences would be statistically insignificant.

The curious (10.82\% of comments and $15.33 \%$ of users) typically posted questions to help clarify the issues at stakes. Questions were of clarification in nature: what are blood clots? Are the vaccines efficient and safe of vaccine? Can we trust vaccines under the status of "emergency use authorization"? Trust was constantly in their mind. They queried about the sources of information posted on the discussion thread and the validity and even questioned the knowledge of other users about statistics in their arguments. Their FB profiles showed that most curious people were young to middle adulthood.

There were a few exploiters $(1.51 \%$ of comments and $0.84 \%$ of users) who came to the site to advertise their products and services, such as the cryptocurrency trading platform, which was irrelevant to the discussion. Those exploiters browsed the FB users' comments and tried to reach them individually with one-to-one replies.

The fans $(3.90 \%$ of comments and $6.33 \%$ of users) expressed their support to the governments or the scientists, as well as to other FB users. They showed their gratitude to the people who worked for the community such as the helpers or the correctors, praised the detectives and paid respect to the mourners.

As expected, the mourners $3.58 \%$ of comments and $5.91 \%$ of users) shared their sympathy to the people who suffered the blood clots or the people who died because of COVID-19. Some mourners acted as helpers or correctors. They stood out in the discussion thread as being emotionally affected by the crisis and, through their postings, they apparently passed their emotions to others.

The manipulators $(6.52 \%$ of comments and $8.44 \%$ of users) did make up conspiracy theories about the safety of vaccines. Most comments were to advise people not to take the vaccines. They quoted unverified sources of information or provided information with missing context. Some manipulators provided incorrect statistics to confuse uninformed and vulnerable audience. Manipulators are themselves victims of conspiracy theories and the "junk science" the believe in.

The detectives $3.10 \%$ of comments and $4.64 \%$ of comments) challenged the manipulators by pointing out questionable statements with dubious sources with the goal to raise public awareness of both the mainstream media news and the FB users. They raised and developed public awareness about those things to clarify the questionable points. 
The correctors (14.48\% of comments and $18.70 \%$ of users) were the most popular convergence behavior. Given the severe nature of the pandemic and the health of the public, they felt the obligation to correct false information. Based on the demographic data, most correctors appeared to be well educated and were motivated to use their knowledge to fight against misleading information. Some correctors criticized the NYT for even posting the news "irresponsibly" causing confusion while others rectified postings from other FB users. The correctors provided valid sources of information to substantiate their claims and fought back fabricated arguments using their own version of mathematics and statistics. A common thread among many correctors was their approach to put the readers on a holistic and balanced perspective (e.g., "there were 8 people with blood clots, but they were among 6.8 million people who took the vaccine.").

The spreaders $(3.58 \%$ of comments and $2.81 \%$ of users) propagated information from other websites that they thought related to the blood clot news. Some spreaders did not check the validity of the information that they shared. Since sharing information is simple on FB, spreaders just "forwarded" the information links rather than added their own opinions. As such, they could spread correct or incorrect information. The difference between spreaders and helpers was that while spreaders just simply forwarded the information from other sources, intentionally or not, the helpers often verified the validity of the sources and added their own explanation to the information that they shared.

\section{Mixed convergence behaviors}

Our study confirmed the existence of convergence behaviors in a crisis. We have detected the presence of all 11 convergence behaviors in our case study. In this section, we are looking for mixed convergence behaviors (e.g., a netizen might be both corrector and spreader), and address the nature of dialogue between them (e.g., a corrector promptly replies to the spreaders or manipulators). There might be a specific interaction pattern that helps us understand how the convergence behaviors affect each other.

The convergence behaviors of FB discussants were compiled and reported in Appendix 2. The majority of participants $(n=346)$ were classified as having only one single convergence behavior. The findings suggest that the convergence behaviors proposed by the literature are prevalent in online crisis-related discussions, and each of the eleven behaviors did manifest independent standing and specific profile.

Appendix 2 also reports discussants who exhibited two simultaneous convergence behaviors in their comments. The helpers-correctors $(n=23)$ tried to offer help and provided useful information to other people; they also corrected misleading information posted by others. Figure 4 shows an example of a netizen who played the roles of both a helper and a corrector in his comments on NYT posting.

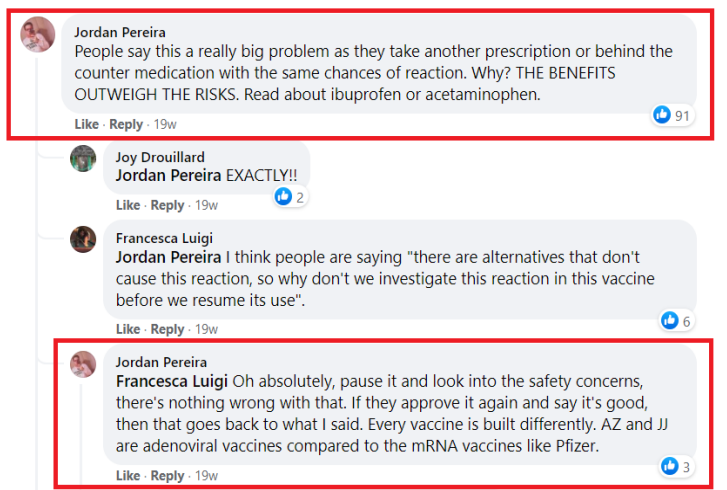

Figure 4. Example of a FB user who was classified as both helper and corrector

The curious-correctors $(n=18)$ frequently visited the NYT posting to search for the information they needed, and at their will, corrected the false or misleading information provided by others.

The curious-helpers $(\mathrm{n}=21)$ looked for information and provided the information they know to other people. While the correctors were willing to argue with manipulators to correct the misleading information, the helpers appeared to avoid conflicts and chose not to engage in heated public debates.

The curious-mourners $(\mathrm{n}=5)$ visited the NYT posting to look for information about the blood clots or the safety of vaccine and mourned the victims. We speculate that those in this category just wanted to get informed, but the sad news they learned led them to become mourners, feeling sorry for the victims. It could also be possible that some of them wanted to express sympathy and became curious with the information provided by others.

Finally, in the dual behavior classification, there were 17 returnees-helpers; and 9 returnees-correctors. Like the majority of the discussants, they visited the NYT posting to gather information to make decision about getting COVID-19 vaccine. As they exposed their thought and reasoning process, they shared the information they knew to others and corrected false information they read. Some of them forcefully argued with manipulators while the others were not.

We were able to identify users who would qualify for a combination of three convergence behaviors to include the "curious-helper-corrector" $(\mathrm{n}=8)$ and "returnee-helper-corrector" $\quad(\mathrm{n}=5)$. People who expressed "curious-helper-corrector" together seemed to be eager to look for knowledge and helped the public 
by providing information and correcting misleading information. As such, they would serve as a valuable member of the cybercommunity, adding value to the quality of the online debate.

As shown in Appendix 2, there were seven users with a mix of four convergence behaviors, nine users with five convergence behaviors, three users with six convergence behaviors, one user with seven convergence behaviors and one user with eight convergence behaviors.

Discussants who were categorized as having multiple convergence behaviors could play a significant role in mediating, regulating, and guiding public discussion about a crisis. At the beginning of the creation of the discussion thread, FB users might have joined the discussion with only one or two primary convergence behaviors. As the debate unfolded, they embraced additional, and possibly unintended, behaviors.

Another encouraging finding was that among the 20 spreaders, only three were found to propagate misleading information. One of them posted a video clip of a medical doctor recommending against vaccination. Another spreader posted a video clip of an anti-vaccine recommendation of a self-proclaimed scientist. The third person posted a website claiming that there were 795 cases of blood clots, reported to be a fake news. We could not verify the identities of the "doctor" and the "scientist".

Most correctors were also helpers (Appendix 2). People who corrected misinformation also offered help to other people when it is possible. However, a helper is not necessarily a corrector. Many helpers were afraid to confront other people in a discussion.

We calculated the correlation coefficients between convergence behaviors in Appendix 2 for users having more than 3 convergence behaviors. The correlation coefficient for curious-helper was 0.43 , manipulatorspreader was 0.31 . The pairs of convergence behaviors were put into the same cluster using the correlation threshold of $30 \%$ in Table 2.

Table 2. Clusters of convergence behaviors

\begin{tabular}{|l|l|}
\hline \multicolumn{1}{|c|}{ Clusters } & \multicolumn{1}{c|}{ Convergence behaviors } \\
\hline Cluster 1 & returnees \\
\hline Cluster 2 & anxious \\
\hline Cluster 3 & curious-helpers \\
\hline Cluster 4 & fans \\
\hline Cluster 5 & exploiters \\
\hline Cluster 6 & mourners \\
\hline Cluster 7 & detectives \\
\hline Cluster 8 & manipulators-spreaders \\
\hline Cluster 9 & correctors \\
\hline
\end{tabular}

The curious-helper users were eager to share their own knowledge and the information they collected from others. They geared up to fight against the manipulator-spreaders. The manipulators-spreaders were keen in making and spreading misinformation.

\section{Summary, implications, and future research}

Extraordinary efforts are required to respond to extreme events [37]. Social media shifted the traditional communication and information-sharing paradigm, which removed many traditional barriers of information distribution [38]. The search for truth in the risk of causing a blood clot by a $J \& J$ vaccine matched the criteria of a crisis. Postings clearly reflected the anxiety of many netizens expressing concerns about their safety, and the urgency of finding a solution to resolve this side effect. Our case study involving 711 netizens with 1,257 postings seems to confirm the validity of that fear. The presence of misinformation is alarming. Out of 364 news postings, $76.37 \%$ of them were classified as fabricated news.

Our study also confirmed the presence of the eleven convergence behaviors reported in the literature. The majority of these netizens appeared to display the convergence behaviors independently. We conducted a clustering analysis to identify possible mixed behaviors. Using a correlation threshold of $30 \%$ or higher, we were only able to group two groups of mixed behaviors: curious-helper and manipulator-spreader. The correlation between helpers and correctors was unexpectedly low at $13 \%$.

When matching the types of convergence behaviors with the profiles of the people posting comments, our data suggests that most helpers and correctors are college graduates, whereas most of the manipulators and spreaders manipulate knowledge about statistics. With the significant role of the correctors shown in our case study, the correctors appear to provide a crowd-source fact-checking opportunity for the general public.

Threatened by the spread of misinformation in the increasingly digital world, people are desperately seeking for truth. Given the rampant mistrust, policy makers and social media operators have yet to find a way to contain the exponential threats of misinformation. How can the average citizen differentiate facts from fiction? While cognitive scientists advocate for the better use of common sense and critical thinking, we have argued through our case study that there exist people who are motivated to fight for misinformation, and they could play a critical and independent role in rectifying misinformation. While the spreaders freely propagate information and 
misinformation, the correctors forcefully attempt to rectify whenever possible.

A contribution of this research is to delineate various convergence behaviors. In crisis situations, emergency management agencies and the news media should pay attention to the conversations between citizens on online platforms to control crisis communication efficiently. While they should more aggressively use social media to provide information to the general public, they should identify the various convergence behaviors and get them involved in the fight for misinformation. Authorities and the public should particularly monitor the spreaders, manipulators and correctors because they can derail the public discourse.

As a result of the attack on the US Capitol on January $6^{\text {th }}, 2021$, Twitter has unilaterally decided to block former US President Trump, until further notice. It was an unprecedented, radical and controversial decision, as the world's most popular micro-blogging platform felt that it was not able to carve out an information policy on its platform. Twitter is not alone. Facebook has been caught and criticized for the inability to formulate a clear use policy. Subba and Bui [11] advocate for the creation of an institutional framework to regulate information exchange and its users on social media. Using a case study of the 400,000-plus members discussion group on helping Haiti deal with its 2010 deathful earthquake, they discovered that there was a grass-root and selforganizing movement to keep Facebook groups from derailing from their original purpose and focus [11].

Social media provide a non-direct interpersonal communication, thus allowing introverted people to express their opinion [39]. Although we did not have specific demographic data to corroborate the claim from [28] research, we contend that it is important to notice the behaviors of introverted people on online discussion. Further steps need to be implemented to formalize a dynamic framework and to improve the emergency management system capacity, especially in developing countries [40].

A limitation of our study is that we only analyzed one short-lived post on the NYT Facebook page. Although the NYT is a respected national newspaper, not everyone has access or is interested in reading it. Therefore, the NYT Facebook users, as a research sample, might not be representative of the general public. Blue-collar workers were significantly underrepresented in the case study. Also, ethnic demographics were not available. We intend to look for more case studies to address these limitations.

\section{Appendix 1: Convergence behavior archetypes as illustrated by the $\mathrm{J} \& \mathrm{~J}$ vaccine decision}

\begin{tabular}{|c|c|}
\hline Convergence Behaviors and their online characteristics & $\begin{array}{l}\text { Examples (note: we reproduce the postings as they } \\
\text { appeared, unedited) }\end{array}$ \\
\hline $\begin{array}{l}\text { The Returnees (Fritz and Mathewson [9]) } \\
\text { Returnees are those who are contemplating about taking a vaccine, became hesitant } \\
\text { and may or may not "return" to the decision to take the vaccine }\end{array}$ & $\begin{array}{l}\text { I'll still take those odds any day of the week over the } \\
\text { alternatives, and won't lose any sleep over them either. }\end{array}$ \\
\hline $\begin{array}{l}\text { The Anxious (Fritz and Mathewson [9]) } \\
\text { The anxious seek and respond to information that may help them reduce their anxiety. } \\
\text { The seekers post questions that may address their concern and the responders respond } \\
\text { to those postings. }\end{array}$ & $\begin{array}{l}\text { Doesn't matter if it's only } 1 \text { in } 7 \text { million. The public } \\
\text { deserves to know of the potential risk...PERIOD }\end{array}$ \\
\hline $\begin{array}{l}\text { The Helpers (Fritz and Mathewson [9]) } \\
\text { Helpers offer help by providing hotline numbers, necessary information or other } \\
\text { helpful information or resources. }\end{array}$ & $\begin{array}{l}\text { People have more chance of dying in an auto accident } \\
\text { on the way to being vaxxed than blod clots from the } \\
\text { vax }\end{array}$ \\
\hline $\begin{array}{l}\text { The Curious (Fritz and Mathewson [9]) } \\
\text { Curious people have minimal personal concerns about the crisis or the victims. On } \\
\text { social media, they read the posts related to the crisis to see the destruction and } \\
\text { arguments of people. They could ask other people about the situation. }\end{array}$ & What the blood clot in the brain? \\
\hline $\begin{array}{l}\text { The Exploiters (Fritz and Mathewson [9]) } \\
\text { Exploiters come to the crisis area for their own personal gains. On social media, they } \\
\text { may try to advertise unnecessary services or products to other people during the crisis. }\end{array}$ & $\begin{array}{l}\text { Collect your EBT cash relief per person and per child } \\
\$ 750 \text {. Follow this link. Thank you } \bigcirc \bigcirc \\
\text { https://sites.google.com/view/sdfghwd/hom }\end{array}$ \\
\hline $\begin{array}{l}\text { The Fans or supporters (Kendra and Wachtendorf }[10]) \\
\text { They show gratitude or support to the rescuers or helpers. On social media, they may } \\
\text { post texts, pictures to say thanks to the rescuers or helpers. }\end{array}$ & $\begin{array}{l}\text { Thank you for sharing this article! } \\
\text { Best statement ever to this whole entire thread! }\end{array}$ \\
\hline $\begin{array}{l}\text { The Mourners (Kendra and Wachtendorf }[10] \text { ) } \\
\text { They memorialize or mourn the victims. On social media, they may post texts, pictures } \\
\text { or Graphics Interchange Format (GIFs) to express mourning. }\end{array}$ & $\begin{array}{l}\text { Every death is terrible. If you think one is bad, wait till } \\
\text { I tell you about this thing that caused } 566,000 \text { of them. }\end{array}$ \\
\hline $\begin{array}{l}\text { The Detectives (Subba and Bui }[11] \text { ) } \\
\text { They watch over the situation, make consideration and take suitable actions. They } \\
\text { could be official or unofficial intelligence gatherers. }\end{array}$ & $\begin{array}{l}\text { JOHNSON \& JOHNSON should be aware of these } \\
\text { risks. }\end{array}$ \\
\hline $\begin{array}{l}\text { The Manipulators (Bunker and Sleigh [13]) } \\
\text { They manipulate the information to promote themselves or to project their personal } \\
\text { characteristics of "power, intelligence, physical attractiveness, sense of entitlement }\end{array}$ & $\begin{array}{l}\text { get back on this post when the vaccine has been out a } \\
\text { year. Vaccines kill \& damage more people then you } \\
\text { think. Research it }\end{array}$ \\
\hline
\end{tabular}




\begin{tabular}{|l|l|}
\hline $\begin{array}{l}\text { and uniqueness". On social media, they may post a status or a commentary with false } \\
\text { information. }\end{array}$ & $\begin{array}{l}\text { This isn't just any blood clot. It's a blood clotting } \\
\text { disorder. Comparing this side effect (from J\&J) to } \\
\text { regular blood clots that can occur when taking birth } \\
\text { The Correctors (Arif et al. [21]) } \\
\text { Correctors correct the misinformation. They point out the information which is accurate comparison. } \\
\text { incorrect and / or provide the correct information. }\end{array}$ \\
$\begin{array}{l}\text { The Spreaders (Leonardi et al. [15]) } \\
\text { Spreaders share the information provided by other people or provided by mainstream } \\
\text { media. Those people can share both correct and / or incorrect information. }\end{array}$ & \begin{tabular}{l} 
453415345991917/ \\
\hline
\end{tabular}
\end{tabular}

\section{Appendix 2: Facebook discussants and their convergence behaviors}

Legends of convergence behaviors: 1 - Returnees, 2 - Anxious, 3 - Helpers, 4 - Curious, 5 - Exploiters, 6 - Fans, 7 Mourners, 8 - Detectives, 9 - Manipulators, 10 - Correctors, 11 - Spreaders
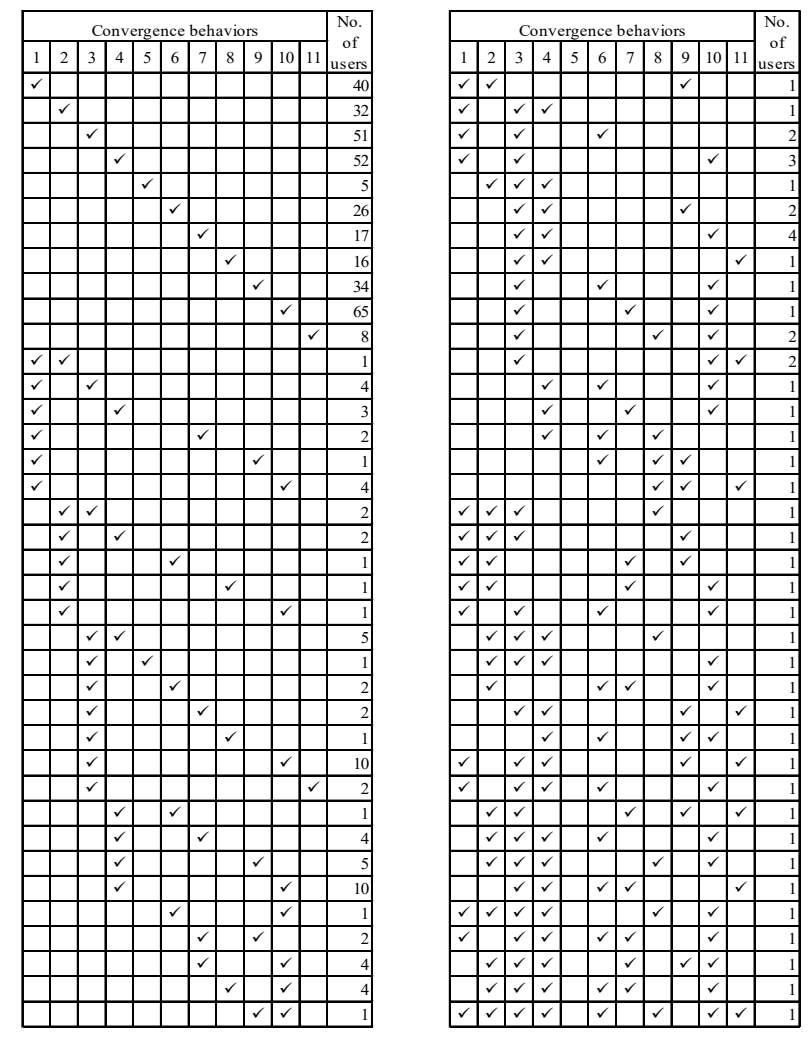

\section{References}

[1] L. Palen, "Online social media in crisis events," Educ. Q., vol. 31, no. 3, pp. 76-78, 2008.

[2] L. G. Pee, "Trust of Information on Social Media: An Elaboration Likelihood Model.," in CONF-IRM, 2012, p. 29.

[3] M. H. M. Sharif, R. Davidson, and I. Troshani, "Exploring Social Media Adoption in Australian Local Government Organizations.," in CONF-IRM, 2013, p. 29.

[4] M. Mirbabaie, D. Bunker, and S. Stieglitz, "The Role of Social Media Network Participants in Extreme Events," 2014.

[5] K. Freberg, "Intention to comply with crisis messages communicated via social media," Public Relat. Rev., vol. 38, no. 3, pp. 416-421, 2012.

[6] M. Mirbabaie and J. Marx, “'Breaking'news: uncovering

sense-breaking patterns in social media crisis communication during the 2017 Manchester bombing," Behav. Inf. Technol., vol. 39, no. 3, pp. 252-266, 2020.

[7] A. Ahmed, "Hypothesizing the aptness of social media and the information richness requirements of disaster management," 2012.

[8] O. Oh, M. Agrawal, and H. R. Rao, "Community intelligence and social media services: A rumor theoretic analysis of tweets during social crises," MIS Q., pp. 407426, 2013.

[9] C. E. Fritz and J. H. Mathewson, "Convergence behavior in disaster: A problem in social control. Washington, DC: National Research Council," Natl. Acad. Sci., 1957.

[10] J. M. Kendra and T. Wachtendorf, "Reconsidering convergence and converger legitimacy in response to the World Trade Center disaster," in Terrorism and disaster: New threats, new ideas, Emerald Group Publishing 
Limited, 2003.

[11] R. Subba and T. Bui, "An exploration of physical-virtual convergence behaviors in crisis situations," in 2010 43rd Hawaii International Conference on System Sciences, 2010, pp. 1-10.

[12] R. Subba and T. Bui, "Online convergence behavior, social media communications and crisis response: An empirical study of the 2015 nepal earthquake police twitter project," in Proceedings of the 50th hawaii international conference on system sciences, 2017.

[13] D. Bunker and A. Sleigh, "Social media use and convergence behaviours during disasters: A cloud with a silver lining or a fog of manipulation," in Proceedings of the Information Systems Research Conference Scandinavia, 2016.

[14] D. Bunker, M. Mirbabaie, and S. Stieglitz, "Convergence behaviour of bystanders: an analysis of 2016 Munich shooting Twitter crisis communication," arXiv Prepr. arXiv2004.08573, 2020.

[15] S. Leonardi, G. Rizzo, and M. Morisio, "Automated Classification of Fake News Spreaders to Break the Misinformation Chain," Information, vol. 12, no. 6, p. 248, 2021.

[16] L. Petersen, L. Fallou, G. Havarneanu, P. Reilly, E. Serafinelli, and R. Bossu, "November 2015 Paris terrorist attacks and social media use: preliminary findings from authorities, critical infrastructure operators and journalists," in ISCRAM 2018 Conference Proceedings, 2018, pp. 629-638.

[17] C. S. Lee, L. Ma, and D. H.-L. Goh, "Why do people share news in social media?," in International Conference on Active Media Technology, 2011, pp. 129 140 .

[18] X. Chen, S.-C. J. Sin, Y.-L. Theng, and C. S. Lee, "Why students share misinformation on social media: Motivation, gender, and study-level differences," $J$. Acad. Librariansh., vol. 41, no. 5, pp. 583-592, 2015.

[19] S. Laato, A. K. M. Islam, M. N. Islam, and E. Whelan, "Why do people share misinformation during the Covid19 pandemic?," arXiv Prepr. arXiv2004.09600, 2020.

[20] T. Hopp, P. Ferrucci, and C. J. Vargo, "Why do people share ideologically extreme, false, and misleading content on social media? A self-report and trace databased analysis of countermedia content dissemination on Facebook and Twitter," Hum. Commun. Res., vol. 46, no. 4, pp. 357-384, 2020.

[21] A. Arif et al., "A closer look at the self-correcting crowd: Examining corrections in online rumors," in Proceedings of the 2017 ACM conference on computer supported cooperative work and social computing, 2017, pp. $155-168$

[22] L. Bode and E. K. Vraga, "Correction Experiences on Social Media During COVID-19," Soc. Media+Soc., vol. 7, no. 2, p. $20563051211008828,2021$.

[23] E. Wang, T. J. Wong, and T. Zhang, "Do Chinese Social Media Correct the Optimistic Bias of Traditional Media," Unpubl. Manuscr., 2019.

[24] A. Roets, “'Fake news': Incorrect, but hard to correct. The role of cognitive ability on the impact of false information on social impressions," Intelligence, vol. 65, pp. 107-110, 2017.
[25] E. K. Vraga and L. Bode, "Using expert sources to correct health misinformation in social media," Sci. Commun., vol. 39, no. 5, pp. 621-645, 2017.

[26] L. Bode and E. K. Vraga, "See something, say something: correction of global health misinformation on social media," Health Commun., vol. 33, no. 9, pp. 1131-1140, 2018.

[27] J. R. Bautista, Y. Zhang, and J. Gwizdka, "Healthcare professionals' acts of correcting health misinformation on social media," Int. J. Med. Inform., vol. 148, p. 104375, 2021

[28] A. F. van Gorp, N. Pogrebnyakov, and E. A. Maldonado, "Just Keep Tweeting: Emergency Responder's Social Media Use Before and During Emergencies," 2015.

[29] M. D. Molina, S. S. Sundar, T. Le, and D. Lee, “"Fake news' is not simply false information: a concept explication and taxonomy of online content," Am. Behav. Sci., vol. 65, no. 2, pp. 180-212, 2021.

[30] X. Zhou and R. Zafarani, "A survey of fake news: Fundamental theories, detection methods, and opportunities," ACM Comput. Surv., vol. 53, no. 5, pp. $1-40,2020$.

[31] D. Murthy, "Digital ethnography: An examination of the use of new technologies for social research," Sociology, vol. 42 , no. 5 , pp. $837-855,2008$.

[32] C. F. Hermann, "Some issues in the study of international crisis," Int. Cris. Insights from Behav. Res., pp. 3-17, 1972.

[33] T. Bui and S. Sankaran, "Foundations for Designing Global Emergency Response Systems (ERS)," in Proceedings of the 3rd International ISCRAM Conference-Newark, NJ, USA, 2006, pp. 72-81.

[34] A. Schwarz, "How publics use social media to respond to blame games in crisis communication: The Love Parade tragedy in Duisburg 2010," Public Relat. Rev., vol. 38, no. 3, pp. 430-437, 2012.

[35] A. R. Shahid and A. Elbanna, "The impact of crowdsourcing on organisational practices: The case of crowdmapping," 2015.

[36] J. W. Creswell, "Educational research: planning," Conduct. Eval., 2012.

[37] M. Turoff, C. White, and L. Plotnick, "Dynamic emergency response management for large scale decision making in extreme hazardous events," in Supporting real time decision-making, Springer, 2011, pp. 181-202.

[38] R. Westbrook, T. Karlgaard, C. White, and J. Knapic, “A holistic approach to evaluating social media's successful implementation into emergency management operations: Applied research in an action research study," Int. J. Inf. Syst. Cris. Response Manag., vol. 4, no. 3, pp. 1-13, 2012.

[39] Y. Amichai-Hamburger, G. Wainapel, and S. Fox, ““ On the Internet no one knows I'm an introvert':

Extroversion, neuroticism, and Internet interaction," Cyberpsychology Behav., vol. 5, no. 2, pp. 125-128, 2002.

[40] C. White, "Disaster Management Systems: Building Capacity for Developing Countries and the Most Vulnerable Among Us," Int. Emerg. Manag. Soc. Conf., 2014. 